\title{
Long-Term Effects of a Multimodal Physiotherapy Program on the Severity of Somatosensory Tinnitus and Identification of Clinical Indicators Predicting Favorable Outcomes of the Program
}

DOI: $10.3766 /$ jaaa. 17147

\author{
Claudia Côté* \\ Isabelle Baril* \\ Catherine-Ève Morency* \\ Samuel Montminy* \\ Mélanie Couture* \\ Jean Leblond $\dagger$ \\ Marianne Roos $\dagger$ \\ Jean-Sébastien Roył:
}

\begin{abstract}
Background: Tinnitus, the perception of sound in the absence of external auditory stimuli, is commonly associated with problems of the auditory system. Head and neck disorders can also be involved in tinnitus emergence. In such cases, the term somatosensory tinnitus is used. Physiotherapy treatments have been identified as a promising avenue in the treatment of somatosensory tinnitus.
\end{abstract}

Purpose: The aim of the study was to explore the effect of a physiotherapy program on the intensity and severity of somatosensory tinnitus and to identify the clinical characteristics of the patients who respond well to this treatment.

Research Design: Quasi-experimental pre-post single-group design.

Study Sample: Thirty-one adults with presumed somatosensory tinnitus.

Intervention: All participants received on average ten physiotherapy treatments over six weeks. Treatments included cervical and thoracic mobilizations, as well as muscular strengthening, stretching, postural instruction, and cervical stabilization.

Data Collection and Analysis: Outcomes were measured at baseline, at the end of the physiotherapy program, and three months later. The primary outcomes were the Tinnitus Handicap Inventory and visual analog scales for loudness and annoyance caused by tinnitus.

After the last evaluation, participants were divided into two groups: improved and unimproved participants. Participants were considered improved if they (1) showed significant improvement in at least two of the three primary outcome measures and (2) indicated subjective improvement. Thereafter, the baseline characteristics that correctly identify participants susceptible to improve significantly following treatment were determined (Cohen's effect size $d>0.8$ ).

Results: A significant improvement in tinnitus intensity was observed at the end of the program. Of the 31 participants, 14 experienced persistent improvement in the intensity of their tinnitus and were classified as improved. Baseline characteristics strongly associated with tinnitus improvement were no increase in tinnitus when exposed to noise $(d=-1.57)$, no family history of tinnitus $(d=-1.16)$, somatosensory

*Centre Intégré Universitaire de santé et services sociaux de La Capitale-Nationale, Quebec City, Canada; †Centre for Interdisciplinary Research in Rehabilitation and Social Integration, Quebec City, Canada; $\$$ Department of Rehabilitation, Faculty of Medicine, Universite Laval, Quebec City, Canada

Corresponding author: Jean-Sébastien Roy, Centre for Interdisciplinary Research in Rehabilitation and Social Integration, Centre Intégré Universitaire de sante et services sociaux de la Capitale-Nationale, Quebec City, Canada G3A 0B4; Email: jean-sebastien.roy@rea.ulaval.ca

This study was supported by the Institut de réadaptation en déficience physique de Québec (IRDPQ) Auditory Disability Research Fund (fonds de recherche en déficience auditive de l'IRDPQ) and the IRDPQ. 
modulation in response to the contraction used to resist pressure applied to the forehead $(d=1.20)$, and recent onset of tinnitus $(d=1.03)$.

Conclusions: This exploratory study showed that a multimodal physiotherapy program is effective in decreasing the severity of tinnitus, principally in individuals presenting with somatosensory tinnitus in combination with specific clinical characteristics.

Key Words: cervical dysfunction, exercises, manual therapy, somatosensory tinnitus

Abbreviations: $\mathrm{CGI}=$ Clinical Global Improvement; $\mathrm{DCN}=$ dorsal cochlear nucleus; $\mathrm{NDI}=$ Neck Disability Index; THI = Tinnitus Handicap Inventory; VAS = visual analog scales; VAS-A = visual analog scales for annoyance; VAS-C = visual analog scales for cervical pain intensity; VAS-L = visual analog scales for loudness

\section{INTRODUCTION}

$\mathrm{T}$ innitus is the involuntary perception of sound in the absence of objective external auditory stimuli (Herraiz, 2008). This condition affects $5-15 \%$ of the population (Elgoyhen and Langguth, 2010) and is typically associated with damage to the auditory system or hearing loss. Its physiological signature is an increase in spontaneous neural activity, or "hyperactivity," in the central auditory system (Wu et al, 2016).

This hyperactivity is believed to occur following damage to the vestibulocochlear nerve (cranial nerve VIII). Any decrease in this nerve's afferent activity, even if only partial, causes a decrease in inhibitory neurotransmitters and their corresponding receptors in the dorsal cochlear nucleus (DCN). The resulting neural disinhibition, combined with excitation from other afferent stimuli, produces increased spontaneous activity in the DCN, which is then projected to central ascending auditory regions, including the inferior colliculus, the medial geniculate body, and the auditory cortex (Dehmel et al, 2012; Shore et al, 2016; Wu et al, 2016). The DCN is thus a multisensory integration center, acting as the auditory system's first site of sensory convergence (Wu et al, 2016).

Although most of the afferent information acquired by the DCN is received from the auditory nerve, sensory input is also obtained from somatosensory pathways such as the trigeminal pathway (which innervates the face, jaw and oral structures) and the dorsal column pathway (which innervates the back of the head, the auricles, the neck, and the upper extremities) (Wu et al, 2016). As injuries or dysfunction to the head or neck represent sources of excitatory somatosensory input, they have the potential to affect auditory pathways and result in either the development of tinnitus or the modulation of its intensity (Sanchez and Rocha, 2011a, Shore et al, 2016).

Despite the fact that deafferentation of auditory pathways has been suggested to be a key factor in the development of tinnitus, $10-15 \%$ of tinnitus patients present with normal audiograms (Shore et al, 2016). It is hypothesized that this phenomenon may be due to the presence of neuropathic changes with no modulation of auditory thresholds in certain tinnitus cases. This, in turn, may be explained by a greater vulnerability to structural damage of the auditory nerve fiber to inner hair cell synapse (induced by noise or aging) when compared with the less vulnerable cochlear transduction mechanism, which determines sound detection thresholds (Kujawa and Liberman, 2009; Shore et al, 2016).

Muscular problems of the head and neck regions, neck pain, and a decrease in cervical mobility are frequently reported to be present in tinnitus cases (Cherian et al, 2013). Because of the apparent association between musculoskeletal disorders of the cervicothoracic vertebral column and the temporomandibular joint, treatment of these disorders is considered to have the potential to decrease or eliminate tinnitus perception. In a systematic review on the effect of physiotherapy treatments in patients with somatic tinnitus, Michiels et al (2016a) conclude that these interventions have an overall positive effect on the severity of tinnitus. The authors, however, also found that meta-analysis of the data from included studies was impossible because of the heterogeneity of the outcome measurements and of the diagnostic criteria used to identify somatic tinnitus cases. In addition, it remains unknown why certain individuals respond to the treatment, whereas others do not.

The objectives of this study were to explore the effect of a multimodal physiotherapy program on the intensity of somatosensory tinnitus in adults and to determine factors that can be used to accurately predict or identify individuals susceptible to respond positively to the intervention.

\section{METHODS}

\section{Participants}

Thirty-one participants presenting with tinnitus that was suspected to have a somatosensory component were recruited from the CIUSSS de la CapitaleNationale (facility IRDPQ) Auditory Disability Program waiting list and from a local association for individuals with tinnitus. To be included, participants needed to be aged 18 years or older and present with a somatic component to their tinnitus, as described in the 
criteria established by Sanchez and Rocha (2011b): manifestation of tinnitus following cervical trauma or manipulations, or simultaneous occurrence with symptoms such as pain and tension in the neck, head, or jaw; concurrent increase of tinnitus intensity and cranial/ cervical/thoracic pain; inadequate posture at rest, when sleeping, and at work; and bruxism or temporomandibular joint problems.

The exclusion criteria were the following: recent manifestation or aggravation of ear-related tinnitus (sudden deafness, ear infection, cochlear hydrops, acoustic or tympanic trauma, etc.); injury to the spinal cord; cochlear or bone conduction implants; advanced osteoporosis; rheumatoid arthritis; and recent cortisone infiltrations. Participants were also excluded if their pain or psychoactive medications were modified at any time over the course of the treatment period. This project was approved by the sectorial rehabilitation and social integration research ethics committee of the CIUSSS de la Capitale-Nationale (project \#2013-344). All potential participants signed informed consent forms.

\section{Study Design}

A single-group pre-post quasi-experimental study design was used (Table 1). This study included three evaluation sessions before the physiotherapy program, one evaluation at the end of the program (T1) and one final evaluation three months after the end of the program (T2). All participants took part in 8-12 physiotherapy treatments over a period of six weeks. The evaluation sessions were carried out by an audiologist at the CIUSSS de la Capitale-Nationale that was not involved in the intervention, whereas the physiotherapy program was performed by a physiotherapist specialized in manual therapy, who was blinded to the results of the baseline evaluations.

The Tinnitus Research Initiative guidelines on clinical evaluation and outcome measures (Langguth et al, 2007) were used to determine the study variables. In addition to the Tinnitus Research Initiative's essential and strongly recommended items (i.e., detailed case history, complete aural examination including psychoacoustic tinnitus measures, physical examination, and minimum of two validated questionnaires on tinnitus severity), measures of cervical pain and functional limitation, anxiety levels, and the number of somatosensory tinnitus modulations were documented.

To determine the stability of the condition before beginning the physiotherapy program, participants took part in three separate preintervention baseline evaluations, which were carried out once a week, and in which main outcomes were measured. Thus, tinnitus loudness (using visual analog scales for loudness [VAS-L]), tinnitus annoyance (using visual analog scales for annoyance [VAS-A]) (Adamchic et al, 2012), and cervical pain intensity (using visual analog scales for cervical pain intensity [VAS-C]) were measured on three occasions before treatment. Questionnaires on tinnitus severity (Tinnitus Handicap Inventory [THI]) (Ghulyan-Bédikian et al, 2010) and cervical pain-related disability (Neck Disability Index [NDI]) (WlodykaDemaille et al, 2002) were administered twice over the same three-week preintervention period. Considering the fluctuating nature of somatosensory tinnitus (Levine, 2004), these repeated measures were believed to be particularly pertinent.

During the first evaluation session (first of the three preintervention baseline evaluations), a detailed history, including 35 questions on participants' personal and clinical characteristics was administered as recommended by the Tinnitus Research Initiative guidelines (Langguth et al, 2007). Because of the fact that the presence of anxiety has been shown to be related to increased tinnitus severity, participants were also required to complete the Beck Anxiety Inventory (Freeston et al, 1994). Screening pertaining to somatosensory tinnitus modulation (somatic testing: battery of 25 isometric head, neck, and jaw contractions) (Levine et al, 2007) was also performed, followed by a complete audiological examination including otoscopy (ear examination), audiometry from $250 \mathrm{~Hz}$ to $16,000 \mathrm{~Hz}$,

Table 1. Study Design

\begin{tabular}{|c|c|c|c|c|c|}
\hline \multicolumn{3}{|c|}{ Phase $A_{1}$ : Baseline } & \multirow{2}{*}{$\begin{array}{c}\text { Phase B: Treatment } \\
\text { Physiotherapy program }(2 \times / \text { week })\end{array}$} & \multicolumn{2}{|c|}{ Phase $\mathrm{A}_{2}$ : Post-treatment } \\
\hline & T0 & & & $\mathrm{T} 1$ & $\mathrm{~T} 2$ \\
\hline Week 1 & Week 2 & Week 3 & & Post 1 week & Post 12 weeks \\
\hline 3 VASs & & & & 3 VASs & 3 VASs \\
\hline THI & & 3 VASs & & THI & $\mathrm{THI}$ \\
\hline NDI & 3 VASs & $\mathrm{THI}$ & & NDI & NDI \\
\hline $\begin{array}{l}\text { Audiological } \\
\text { testing/Somatic } \\
\text { testing }\end{array}$ & & NDI & & $\begin{array}{l}\text { Audiological } \\
\text { testing/Somatic } \\
\text { testing CGI }\end{array}$ & CGI \\
\hline
\end{tabular}


impedancemetry, otoacoustic emissions testing (transient-evoked otoacoustic emission [TEOAE]/distortion product otoacoustic emission [DPOAE]), and psychoacoustic tinnitus measurements (tinnitus matching, minimum masking level, residual inhibition, and equivalent loudness at $1 \mathrm{kHz}$ ). It should be noted that all participants had already undergone an examination by an ear, nose, and throat specialist before admission into the program.

Thereafter, participants took part in the standardized physiotherapy program. One week following the end of the treatment (T1), an audiologic examination was used to determine whether there had been any changes in auditory status over the course of the intervention. Tinnitus equivalent loudness at $1 \mathrm{kHz}$ was also reevaluated. At both the T1 (one week post-treatment) and T2 (three months post-treatment) evaluations, all self-administred questionnaires (THI, NDI et VAS-L, and VAS-A et VAS-C) were once again completed by the participants, in addition to a question pertaining to global change since the initial session (Clinical Global Improvement [CGI]).

\section{Study Variables}

Tinnitus severity was measured with VAS, as well as with the validated French version of the THI (GhulyanBédikian et al, 2010).

Visual analog scales evaluating the loudness and annoyance caused by tinnitus (VAS-L and VAS-A) are valid and reliable measures (intraclass correlation coefficient $=0.79$ and 0.78 , respectively) that can be used to establish a decrease in severity of chronic tinnitus. The minimal clinically important difference is between 10 and 15 points on a scale from 0 to 100 (Adamchic et al, 2012).

The THI (Ghulyan-Bédikian et al, 2010) is a questionnaire that can be used to quantify the psychoemotional and functional components of the handicap imposed by tinnitus. It is composed of 25 questions with three possible responses: yes $=4$ points, sometimes $=2$ points, or no $=0$ point. The total score can thus vary from 0 to 100 points, with a greater score indicating a greater perceived handicap. The internal consistency is excellent (Cronbach's $\alpha=0.90$ ), and the minimal clinically important difference is seven points (Zeman et al, 2011).

Subjective improvement in tinnitus was evaluated using the CGI questionnaire, which is a 7-level scale that measures a patient's clinical improvement following a specific treatment (1: very much better; 2 : much better; 3: somewhat better; 4: no change; 5 : somewhat worse; 6 : much worse; and 7: very much worse). Participants were considered to have improved if they had a score of 1,2 , or 3 .

Cervical pain intensity was measured with a VAS (Childs et al, 2005), as well as with a French version of the NDI (Wlodyka-Demaille et al, 2002). The NDI is a 10-item auto-administered questionnaire which evaluates disability related to neck pain. Responses to each question are scored on a 6-level Likert scale $(0=$ no disability; $5=$ total disability $)$ for a possible total of 50 points $(0=$ no disability; $50=$ total disability). The reliability (intraclass correlation coefficient $=$ $0.73-0.98$ ) and responsiveness of this questionnaire have been demonstrated. The minimal detectable change is 10.2 points and the minimal clinically important difference is 7.5 points (Young et al, 2009).

\section{Intervention-Multimodal Physiotherapy Program}

Each participant took part in two 60-minute treatment sessions per week for four to seven consecutive weeks. The treatment plan was determined and adjusted in accordance with the results of the initial physiotherapy evaluation including the following.

- Subjective evaluation: problem history; description of pain and tinnitus; presence of headaches, nausea, vomiting, vertigo, dizziness, numbness, and visual problems; and sleep quality and sleep posture.

- Objective evaluation: posture, active and passive cervical mobility (CROM, Youdas et al, 1992), temporomandibular mobility (with a metric ruler), active and passive shoulder mobility (using a goniometer and an inclinometer), deep neck flexor recruitment, manual muscle testing of the upper extremities and of the thoracic girdle, and a neurological examination (reflexes, dermatomes, myotomes, and neuromeningeal mobility [neurodynamic assessment] with upper limb tension testing). The physiotherapist completed the standardized biomechanical evaluation by testing intervertebral segmental mobility with anteroposterior mobilization techniques. This type of testing, in which the mobility is judged to be normal, hypomobile, or hypermobile, has been shown to be sensitive $(>0.80)$ as well as specific $(>0.70)$ (Sandmark and Nisell, 1995; Rey-Eiriz et al, 2010). It is also an evaluation procedure recommended by the American Physical Therapy Association Neck Pain clinical practice guidelines.

According to a systematic review published in 2010, treatments combining mobilizations and exercises represent the most efficient interventive approach for decreasing pain levels and improving function in the case of cervical musculoskeletal disorders (Miller et al, 2010). The treatments used in this study thus included cervical, thoracic, and temporomandibular manual therapy. For the cervical and upper thoracic spine, the physiotherapist used any of the following mobilization techniques: rotations, lateral glides in neutral, 
postero-anterior glides, postero-inferior-medial glides, or antero-superior-anterior glides (10 repetitions held for 30 seconds with a force grade of 3 to 4 as described by Maitland et al [2005]). For the temporomandibular joint, distraction, lateral, and medial glides, as well as masseter, pterygoid, and temporalis muscle release techniques were performed when needed. Cranial mobilization techniques were used when necessary, until tissue relaxation was achieved. The program also included stretches (such as axial extension exercises, as well as pectoralis [major and minor], upper trapezius, levator scapulae, and sternocleidomastoid muscle stretches), some given to the participants to carry out on their own and some performed passively by the physiotherapist, as well as neuromeningeal (upper limb tension test) and myofascial mobilizations. A pressure biofeedback unit was used to ensure efficient recruitment of the deep neck flexors.

Participants were required to practice a standardized home exercise program taught to them by the physiotherapist, three to four times a week (Table 2). The program included cervical stabilization exercises, either deep neck flexor static recruitment in supine and in sitting as well as dynamic recruitment (deep neck

Table 2. Parameters of the Home Exercise Program

\begin{tabular}{|c|c|c|}
\hline Item Category & Item No. & Abbreviated Item Description \\
\hline What: & 1 & $\begin{array}{l}\text { Type of exercise equipment } \\
\text { - Resistance band (blue, black) } \\
\text { - Dumbbells ( } 1 \text { to } 5 \text { lbs) } \\
\text { - Ball }\end{array}$ \\
\hline Who: & 2 & $\begin{array}{l}\text { Qualifications of the exercise instructor } \\
\text { Physiotherapist }\end{array}$ \\
\hline \multirow[t]{17}{*}{ How: } & 3 & $\begin{array}{l}\text { Whether exercises are performed individually or in a group } \\
\text { Individually }\end{array}$ \\
\hline & 4 & Whether exercises are supervised or unsupervised \\
\hline & & $\begin{array}{l}\text { Supervised during the physiotherapy treatments; unsupervised for home exercises (strengthening, stretching, } \\
\text { and cervical stabilization) }\end{array}$ \\
\hline & 5 & Measurement and reporting of adherence to exercise \\
\hline & & $\begin{array}{l}\text { At each treatment session, participants were asked to report the number of times the exercises were performed } \\
\text { at home }\end{array}$ \\
\hline & 6 & Details of motivation strategies \\
\hline & & Patient education about the importance of doing the exercises \\
\hline & 7 & Decision rules for progressing the exercise program \\
\hline & & $\begin{array}{l}\text { Strengthening exercises started with } 2 \text { sets of } 15 \text { repetitions. Fatigue at the end of the sets was expected. The } \\
\text { load or resistance was increased when there was no muscular fatigue at the end of the sets. }\end{array}$ \\
\hline & 8 & Each exercise is described so that it can be replicated \\
\hline & & Figures and instructions of all the strengthening exercises performed were given to each participant \\
\hline & 9 & Content of any home program component \\
\hline & & Cervical stabilization, strengthening, and stretching \\
\hline & 10 & Nonexercise components \\
\hline & & Pain management techniques: self-massage, positioning, and postural awareness \\
\hline & 11 & How adverse events that occur during exercise are documented and managed \\
\hline & & Documented in the evolutionary notes of the physiotherapist; managed during the physiotherapy treatments \\
\hline \multirow[t]{2}{*}{ Where: } & 12 & Setting in which exercises are performed \\
\hline & & $\begin{array}{l}\text { Supervised at the physiotherapy department of a rehabilitation center } \\
\text { Unsupervised at participant's home }\end{array}$ \\
\hline \multirow{3}{*}{$\begin{array}{l}\text { When, How } \\
\text { Much: }\end{array}$} & 13 & Detailed description of the exercises (e.g., sets, repetitions, duration, and intensity) \\
\hline & & For strengthening exercises: 2 sets of 15 repetitions with muscle fatigue expected at the end of the sets \\
\hline & & $\begin{array}{l}\text { For stretching: } 4-5 \text { repetitions held for } 20 \text { seconds } \\
\text { For cervical stabilization exercises: two sets of ten repetitions without muscle fatigue }\end{array}$ \\
\hline \multirow[t]{3}{*}{ Tailoring: } & 14 & $\begin{array}{l}\text { Whether exercises are generic ("one size fits all") or tailored to the individual } \\
\text { Tailored to the individual }\end{array}$ \\
\hline & 15 & $\begin{array}{l}\text { Decision rule that determines the starting level for exercise and based on the physiotherapist's analysis of each } \\
\text { participant's clinical }\end{array}$ \\
\hline & & Portrait \\
\hline \multirow[t]{2}{*}{ How Well: } & 16 & Whether the exercise intervention is delivered and performed as planned \\
\hline & & $\begin{array}{l}\text { Initially, exercises were taught and practiced during the physiotherapy treatments but performed at home. The } \\
\text { exercises were revised at each physiotherapy treatment and adjusted according to the performance. }\end{array}$ \\
\hline
\end{tabular}


flexor recruitment combined with upper extremity movement). Temporomandibular, upper extremity, and thoracic girdle strengthening exercises were proposed when weaknesses in these areas were found. Participants also received postural coaching depending on the problems discovered at the initial evaluation. If no improvement was seen on tinnitus intensity after six sessions, or if the condition was re-established or could not be further improved, the program was ceased.

\section{Statistical Analysis}

First, the scores on the self-reported questionnaires and VASs completed during the evaluation sessions before the physiotherapy program were averaged to determine the baseline scores (T0). Thereafter, to determine the effect of the intervention program on tinnitus severity for the group of participants as a whole, a one-way (T0, T1, and $\mathrm{T} 2$ ) repeated measures ANOVA was realized (post hoc Bonferroni).

The next step of the analysis aimed to determine the baseline characteristics allowing accurate identification of the participants susceptible to improve significantly as a result of the treatment. Two groups were created for this purpose. As data varied greatly from person to person, the effect of the program was first evaluated on an individual basis, for each participant. Baseline THI, VAS-L, and VAS-A scores were averaged and the corresponding 95\% confidence intervals calculated. Post-treatment values exceeding the 95\% confidence intervals were considered to reflect significant improvement in relation to the baseline measurements. Each participant who showed significant improvement in at least two of the main tinnitus outcome measures (thus, excluding the cervical pain intensity measure), as well as subjective improvement according to the CGI, with persistence of these criteria over three months, were assigned to the "improved participants" group. All others were considered "unimproved." Data from the two groups were then compared. Effect sizes, determined with Cohen's $d$ in the present study, indicate the direction and strength of the association between a given characteristic and the improvement achieved following treatment. A positive $d$ value indicates that the presence, as opposed to the absence, of the given characteristic is associated with improvement. A negative $d$ value, on the other hand, demonstrates that the improvement is associated with the absence of the characteristic. Effect sizes are generally considered to be "small" at 0.2 , "medium" at 0.5 , and "large" at 0.8 . An absolute $d$ value of one or greater indicates that the association is strong enough to be perceived in a clinical setting. In other words, on an individual level, the presence of the characteristic signifies probable improvement.

\section{RESULTS}

$\mathrm{T}$ hirty-one (31) participants (19 men and 12 women, aged from 34 to 75 [56 \pm 13 years]) completed the study. Significant improvement was observed in all mean scores of the dependent variables evaluating tinnitus intensity (VAS-L, VAS-A, and THI; $p \leq 0.001$ ) and neck pain (VAS-C and NDI; $p \leq 0.001$ ) following the physiotherapy program (Table 3 ). Post hoc tests demonstrated that these significant improvements were present at both $\mathrm{T} 1$ and $\mathrm{T} 2$ when compared with baseline measurements. Results also reveal an average improvement, between $\mathrm{T} 0$ and $\mathrm{T} 2$, of 13 points on the VAS-L, 15 points on the VAS-A, 21 points on the VAS-C, 15 points on the THI, and 9 points on the NDI.

Of the 31 participants, 14 were considered "improved" and 17 "unimproved" (see Figures 1-5 for the results of each group). No statistical analysis was performed on these groups because the groups were established based on these outcomes. The participants in the improved group received an average of two more treatments than those in the unimproved group (11.4 \pm 2.6 treatments versus $9.5 \pm 2.5$ treatments; $p=0.049$ ). The content of the physiotherapy intervention was similar for both groups. No one experienced significant deterioration of their tinnitus following treatments.

The effect sizes are presented in Table 4 for each study variable. The two clinical characteristics that were found to be associated with tinnitus improvement and that had a large effect size $(d \geq 1.0)$ are (a) the presence of somatic modulation of the tinnitus in response to Levine's 7th manoeuvre and (b) recent onset of the tinnitus. Other interesting associations ( $d$ between 0.75 and 1) related to improvement include sudden onset of the tinnitus, somatic modulation in response to Levine's 11th and 16th manóuvres, high pain and headache occurrence, fluctuating tinnitus, and asymmetrical tinnitus.

Conversely, the absence of the following two characteristics is susceptible to predict improvement prompted by the treatment $(d \leq-1)$ : (a) an increased

Table 3. Mean Scores ( \pm Standard Deviation) at Pre- and Postintervention

\begin{tabular}{lcccc}
\hline & Baseline $\dagger$ & Post 1 Week & Post 12 Weeks & $p$ \\
\hline VAS-L & $59.4 \pm 17.2$ & $45.1 \pm 24.2^{*}$ & $46.5 \pm 24.2^{*}$ & $\leq 0.001$ \\
VAS-A & $56.5 \pm 20.5$ & $40.0 \pm 25.4^{*}$ & $41.5 \pm 23.2^{*}$ & $\leq 0.001$ \\
VAS-C & $41.6 \pm 25.0$ & $20.6 \pm 24.3^{*}$ & $20.9 \pm 24.1^{*}$ & $\leq 0.001$ \\
THI & $48.2 \pm 22.7$ & $32.7 \pm 22.7^{*}$ & $33.6 \pm 21.9^{*}$ & $\leq 0.001$ \\
NDI & $23.2 \pm 13.20$ & $12.5 \pm 10.4^{*}$ & $14.3 \pm 11.4^{*}$ & $\leq 0.001$
\end{tabular}

${ }^{*}$ Significant difference $(p<0.001)$ compared with the baseline score. $\dagger$ Mean scores ( \pm standard deviation) of the self-reported questionnaires and VASs completed before the physiotherapy program (two or three evaluations). 


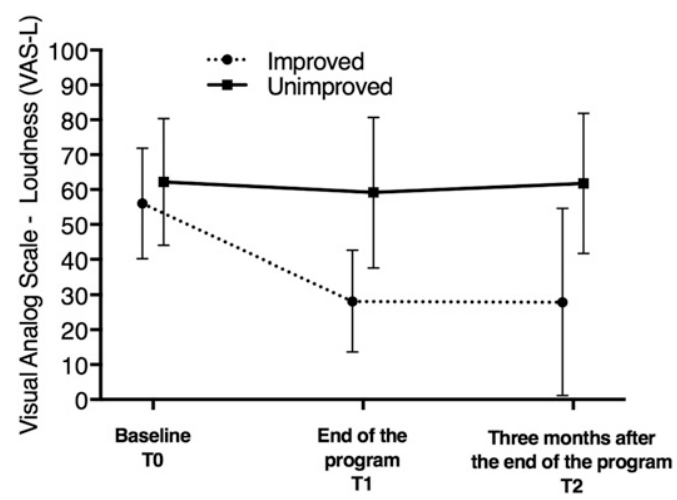

Figure 1. VAS-L (tinnitus loudness pre-post treatment).

tinnitus in response to loud noise and (b) family history of tinnitus. Note that a $d$ value could not be obtained for "medication aggravates tinnitus" (analgesics, anti-inflammatories, and antibiotics), but this characteristic was found to have a significant effect size $(p=0.02)$. The absence of the following characteristic is also related to improvement of the condition, although less significantly ( $d$ close to -0.8 ): somatic modulation in response to manoeuvre \#9.

\section{DISCUSSION}

$\mathrm{T}$ his study aimed to explore the effect of a multimodal physiotherapy program on tinnitus severity in persons presenting with a somatosensory component to their condition. On average, tinnitus severity and cervical pain were significantly decreased following participation in the program. The secondary objective was to determine factors that may be used to select the individuals who will respond positively to this type of treatment. The strength of the associations obtained for certain characteristics signifies that they may accurately be used to identify the candidates that are best suited to the program. Results are summarized in a clinic-friendly decision table (see Supplemental Appendix $\mathrm{S} 1$, available with the online version of this article) whose

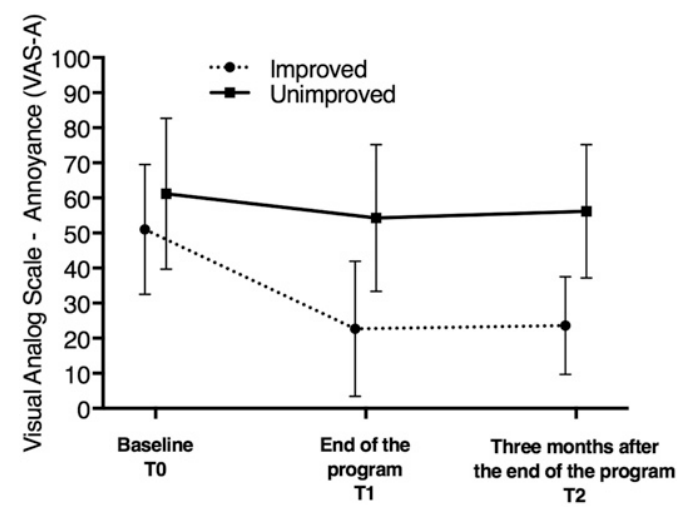

Figure 2. VAS-A (tinnitus annoyance pre-post treatment).

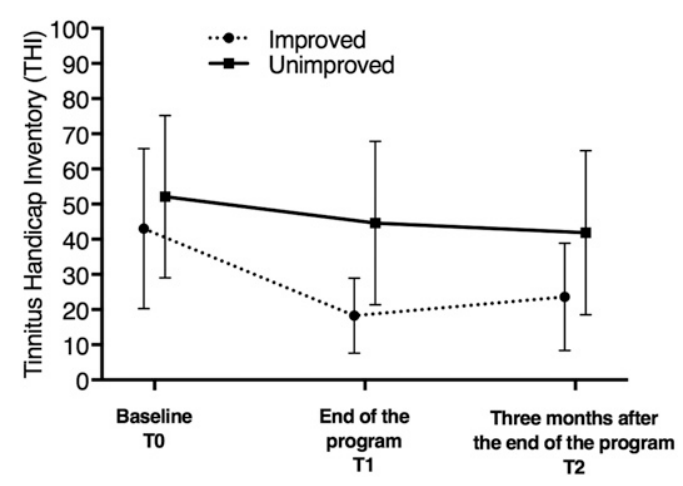

Figure 3. THI (\%) pre-post treatment.

purpose is to forecast the efficiency of the physiotherapy program for a given individual suffering from tinnitus.

Nearly half of the participants maintained a decrease in the severity of their tinnitus for a period of three months following the physiotherapy program. These results concord with those of Levine (2013), which suggest that if the tinnitus is related to myofascial disorders of the head and/or neck, a program which addresses and treats myofascial problems may lead to great improvement of the tinnitus condition. Michiels et al (2016b) also demonstrated the positive effect of a multimodal cervical physiotherapy treatment in individuals with somatosensory tinnitus (tinnitus of cervocogenic causes). In their study, 53\% of the treated participants benefited from a significant decrease in the severity of their tinnitus.

At the beginning of our study, the clinical characteristics of patients who would respond well to physiotherapy treatments were still unknown. However, Levine et al (2007) suggested that tinnitus, which is fluctuating, lateralized, and in which hearing is not problematic or significantly affected, responds well (or better) to somatic treatments, and our results are in agreement with this hypothesis. Very recently, Michiels et al (2017) found that the prognosis is favorable in adults

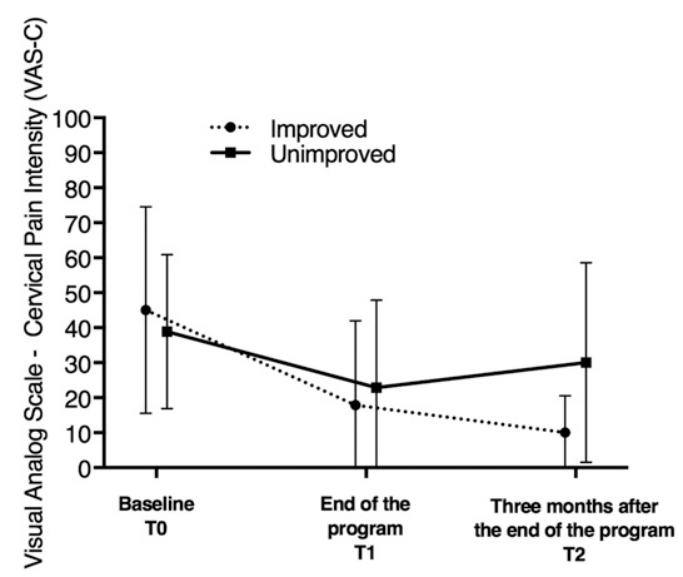

Figure 4. VAS-C (cervical pain pre-post treatment). 


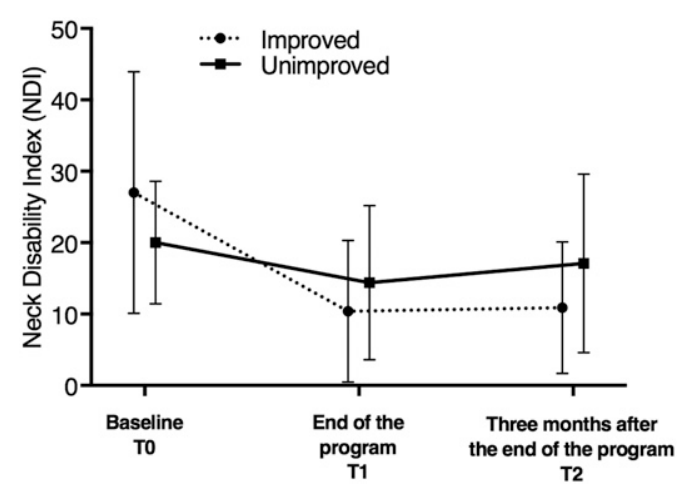

Figure 5. NDI (\%) pre-post treatment.

with somatosensory tinnitus whose symptoms covary with cervical complaints, as well as those presenting with a combination of low frequency tinnitus and tinnitus which increases with the adoption of inadequate cervical posture. Globally, the results of the present study are similar, indicating that the group of "improved" participants is simultaneously the group showing the greatest decrease in cervical pain, as well as including all the participants with low-frequency tinnitus. The participants' profiles also concord with somatosensory tinnitus literature in terms of the fluctuating $(84 \%)$ and asymmetrical $(84 \%)$ nature of the tinnitus, normal hearing for their age $(65 \%)$, and tinnitus which is more frequently perceived in the ear than in the head (84\%) (Levine et al, 2007; Sanchez and Rocha, 2011a; Michiels et al, 2015a).

Levine et al (2007) and Sanchez and Rocha (2011a) demonstrated that approximately two-thirds of patients experienced modulation of their tinnitus with muscular contractions, and that with a series of specific manoeuvres, this percentage increases to about 80 (Levine, 2004). The same phenomenon was observed in our cohort, in which $65 \%$ of the participants, when questioned, reported having observed spontaneous tinnitus modulations with the muscular contractions mentioned previously. Following Levine's somatic testing, $90 \%$ of the participants presented tinnitus modulations; this finding was probable considering our inclusion criteria which comprised at least one somatosensory component of the tinnitus. We did not, however, discover a statistically significant greater number of modulations in the improved participants group at baseline (11.1 for the improved group versus 8.8 for the unimproved group; $p=$ 0.234 ), a finding which supports those of Michiels et al (2015a).

In the group of participants who did not demonstrate significant long-term improvement following treatments, a much higher prevalence of symptoms associated with hearing problems was found. Indeed, the "unimproved" group comprised a large majority of the participants whose tinnitus increases with exposure to loud sound (82\%), as well as containing $100 \%$ of the participants with moderate to severe hearing loss. More subtle observations in this group include a greater occurrence of sound intolerance, average hearing level (pure-tone average) that is higher and more frequently abnormal for the person's age, and low occurrence of normal otoacoustic emissions (DPOAE). A particularly interesting finding is the significantly greater proportion of individuals with a family history of tinnitus (76\%). Tinnitus is not hereditary; hearing loss, however, can have a hereditary component and is generally strongly associated with tinnitus. These observations suggest that although the intention was to recruit tinnitus cases with a somatosensory component, the hearing loss component was perhaps the dominant factor in the manifestation and aggravation of the tinnitus presented by these participants. As such, the treatment which was geared toward the somatic system had no significant long-term effect. As auditory afferences are predominantly situated in the cochlear nucleus, we hypothesize that beyond a certain critical level of neural reorganization from the central primary auditory pathway (following auditory problems), treatment of the secondary auditory pathway (afferent somatosensory pathways) has no persistent effect on tinnitus perception. Levine's (2004) findings support the idea that tinnitus manifests itself beyond a certain neural threshold (neural threshold theory). According to this model, if tinnitus is a result of neural plasticity of auditory origin, and if it passes the perceptive threshold, then treatment of somatic pathways may be insufficient to lower tinnitus perception below the neural threshold of tinnitus perception.

This study found improvement of the cervical condition to equal degrees at the end of interventions in both the "improved" and "unimproved" groups. Michiels et al (2015b) suggested that the presence of cervical pain is an indicator of somatosensory tinnitus, but that this characteristic alone is far from sufficient, as supported by our results.

\section{Study Limitations}

The present study has certain limits, the greatest of which pertains to the lack of control group. A randomized controlled trial, including a no treatment group, may allow for confirmation of the efficiency of this physiotherapy intervention in persons with somatosensory tinnitus who present the clinical characteristics identified in this study. Furthermore, a greater number of participants would have permitted the utilization of logistic regression and the development of a clinical prediction rule. A larger sample would also have supported the dichotomization of the participants 
Table 4. Baseline Characteristics Allowing Differentiation between Groups (Improved or Unimproved)

\begin{tabular}{|c|c|c|c|c|c|}
\hline $\begin{array}{l}\text { Clinical Baseline Characteristics (From Evaluation, } \\
\text { Questionnaire and History Case) }\end{array}$ & $\begin{array}{l}\text { All Participants } \\
\qquad(\mathrm{n}=31)\end{array}$ & $\begin{array}{l}\text { Improved } \\
\text { Participants } \\
(\mathrm{n}=14)\end{array}$ & $\begin{array}{l}\text { Unimproved } \\
\text { Participants } \\
(\mathrm{n}=17)\end{array}$ & $\begin{array}{l}\text { Effect } \\
\text { Size }^{\star} d\end{array}$ & $p$ \\
\hline \multicolumn{6}{|l|}{ Sociodemographic Information } \\
\hline Age (years) & $55.6 \pm 12.1$ & $54.9 \pm 12.2$ & $56.2 \pm 12.4$ & -0.11 & 0.39 \\
\hline Gender (male) & $61 \%$ & $63 \%$ & $60 \%$ & -0.06 & 0.89 \\
\hline \multicolumn{6}{|l|}{ Audiological variables } \\
\hline Abnormal hearing according to age (ISO 7029) & $35 \%$ & $29 \%$ & $41 \%$ & -0.31 & 0.47 \\
\hline Decreased sound tolerance & $45 \%$ & $36 \%$ & $53 \%$ & -0.39 & 0.35 \\
\hline Increased tinnitus following loud noise (yes/no) & $56 \%$ & $21 \%$ & $82 \%$ & -1.57 & 0.00 \\
\hline Recent onset of tinnitus (years) & $6.8 \pm 10.2$ & $1.6 \pm 1.4$ & $11.1 \pm 12.3$ & 1.03 & 0.00 \\
\hline Family history of tinnitus & $52 \%$ & $29 \%$ & $76 \%$ & -1.16 & 0.02 \\
\hline Sudden onset of tinnitus & $52 \%$ & $71 \%$ & $35 \%$ & 0.84 & 0.06 \\
\hline Low frequency dominant tinnitus pitch & $13 \%$ & $29 \%$ & $0 \%$ & $\mathrm{n} / \mathrm{a}^{*}$ & 0.07 \\
\hline Fluctuating tinnitus & $84 \%$ & $93 \%$ & $77 \%$ & 0.76 & 0.25 \\
\hline Tinnitus perceived in the ears (vs. elsewhere in the head). & $84 \%$ & $100 \%$ & $71 \%$ & $\mathrm{n} / \mathrm{a}^{*}$ & 0.08 \\
\hline Asymmetrical tinnitus & $84 \%$ & $93 \%$ & $76 \%$ & 0.76 & 0.25 \\
\hline $\begin{array}{l}\text { Spontaneous observation of somatosensory tinnitus } \\
\text { modulations }\end{array}$ & $65 \%$ & $64 \%$ & $65 \%$ & -0.01 & 0.98 \\
\hline VAS-A (/100) & $57 \pm 21$ & $51 \pm 19$ & $61 \pm 22$ & -0.51 & 0.09 \\
\hline VAS-L (/100) & $59 \pm 17$ & $56 \pm 16$ & $62 \pm 18$ & -0.36 & 0.15 \\
\hline $\mathrm{RI}$ & $74 \%$ & $86 \%$ & $65 \%$ & 0.65 & 0.21 \\
\hline Normal DPOAE's & $32 \%$ & $43 \%$ & $24 \%$ & 0.49 & 0.27 \\
\hline PTA $(0.5-1,2 \mathrm{kHz}) \mathrm{dB}$ & $15 \pm 16$ & $12 \pm 10$ & $18 \pm 20$ & -0.42 & 0.37 \\
\hline $\mathrm{THI}(/ 100)$ & $48 \pm 23$ & $43 \pm 23$ & $52 \pm 2$ & -0.38 & 0.11 \\
\hline HF PTA $(10,11.2,12.5,14,16 \mathrm{kHz}) \mathrm{dB}$ & $69 \pm 24$ & $65 \pm 17$ & $72 \pm 28$ & -0.28 & 0.19 \\
\hline Normal TEOAE's & $45 \%$ & $57 \%$ & $53 \%$ & 0.09 & 0.82 \\
\hline Decreased tinnitus loudness eq. At $1 \mathrm{kHz}(\mathrm{RE})$ in $\mathrm{dB}$ & $-3.6 \pm 8.5$ & $-4.8 \pm 9.0$ & $-3.6 \pm 6.8$ & -0.15 & 0.49 \\
\hline Decreased tinnitus loudness eq. At $1 \mathrm{kHz}(\mathrm{LE})$ in $\mathrm{dB}$ & $-4.4 \pm 10.4$ & $-5.1 \pm 12.9$ & $-3.0 \pm 7.0$ & -0.21 & 0.39 \\
\hline \multicolumn{6}{|l|}{ Other health issues } \\
\hline Moderate to severe anxiety (BAI > 15/63) & $45 \%$ & $29 \%$ & $59 \%$ & -0.70 & 0.11 \\
\hline Presence of pain & $71 \%$ & $86 \%$ & $59 \%$ & 0.79 & 0.13 \\
\hline Headache & $45 \%$ & $64 \%$ & $29 \%$ & 0.81 & 0.07 \\
\hline Decreased sleep quality due to tinnitus & $37 \%$ & $23 \%$ & $50 \%$ & -0.66 & 0.17 \\
\hline VAS-C (/100) & $42 \pm 25$ & $45 \pm 30$ & $39 \pm 22$ & 0.26 & 0.24 \\
\hline $\mathrm{NDI}(/ 100)$ & $23 \pm 13$ & $27 \pm 17$ & $20 \pm 9$ & 0.54 & 0.22 \\
\hline $\begin{array}{l}\text { Medication aggravates tinnitus (analgesics, anti- } \\
\text { inflammatories, and antibiotics) }\end{array}$ & $23 \%$ & $0 \%$ & $41 \%$ & $\mathrm{n} / \mathrm{a}^{*}$ & 0.02 \\
\hline Medication improves tinnitus (analgesics, psychotropics) & $19 \%$ & $29 \%$ & $12 \%$ & 0.61 & 0.26 \\
\hline Vertigo & $39 \%$ & $29 \%$ & $47 \%$ & -0.44 & 0.31 \\
\hline \multicolumn{6}{|l|}{ Somatic testing } \\
\hline $\begin{array}{l}\text { Number of modulations elicited with somatic testing } \\
\text { (Levine/25); all manoeuvers use maximal force applied } \\
\text { by the examiner }\end{array}$ & $9.8 \pm 5.6$ & $11.1 \pm 5.2$ & $8.8 \pm 5.9$ & 0.43 & 0.19 \\
\hline \#1 Clench teeth together & $55 \%$ & $43 \%$ & $65 \%$ & -0.49 & 0.24 \\
\hline \#2 Open the mouth (wide) & $45 \%$ & $57 \%$ & $35 \%$ & 0.49 & 0.24 \\
\hline \#2A Open the mouth with restorative pressure & $32 \%$ & $43 \%$ & $24 \%$ & 0.49 & 0.27 \\
\hline \#3 Protrude jaw & $45 \%$ & $36 \%$ & $53 \%$ & -0.39 & 0.35 \\
\hline \#3A Protrude jaw with restorative pressure & $48 \%$ & $50 \%$ & $47 \%$ & 0.06 & 0.87 \\
\hline \#4 Slide jaw to left & $29 \%$ & $36 \%$ & $24 \%$ & 0.33 & 0.47 \\
\hline \#4A Slide jaw to left with restorative pressure & $35 \%$ & $36 \%$ & $35 \%$ & 0.01 & 0.98 \\
\hline \#5 Slide jaw to right & $35 \%$ & $21 \%$ & $47 \%$ & -0.65 & 0.16 \\
\hline \#5A Slide jaw to right with restorative pressure & $48 \%$ & $50 \%$ & $47 \%$ & 0.06 & 0.87 \\
\hline \#6 Retract jaw & $42 \%$ & $57 \%$ & $29 \%$ & 0.64 & 0.14 \\
\hline $\begin{array}{l}\text { \#7 With the head in neutral position contractions made to } \\
\text { resist pressure applied by the examiner to the forehead }\end{array}$ & $52 \%$ & $79 \%$ & $29 \%$ & 1.20 & 0.02 \\
\hline $\begin{array}{l}\text { \#8 With the head in neutral position contractions made to } \\
\text { resist pressure applied by the examiner to the occiput }\end{array}$ & $32 \%$ & $36 \%$ & $29 \%$ & 0.16 & 0.71 \\
\hline
\end{tabular}




\begin{tabular}{|c|c|c|c|c|c|}
\hline $\begin{array}{l}\text { Clinical Baseline Characteristics (From Evaluation, } \\
\text { Questionnaire and History Case) }\end{array}$ & $\begin{array}{l}\text { All Participants } \\
\qquad(\mathrm{n}=31)\end{array}$ & $\begin{array}{l}\text { Improved } \\
\text { Participants } \\
(\mathrm{n}=14)\end{array}$ & $\begin{array}{l}\text { Unimproved } \\
\text { Participants } \\
\quad(\mathrm{n}=17)\end{array}$ & $\begin{array}{l}\text { Effect } \\
\text { Size* }^{*}\end{array}$ & $p$ \\
\hline $\begin{array}{l}\text { \#9 With the head in neutral position, contractions made to } \\
\text { resist pressure applied by the examiner to the vertex }\end{array}$ & $29 \%$ & $14 \%$ & $41 \%$ & -0.79 & 0.13 \\
\hline $\begin{array}{l}\text { \#10 With the head in neutral position, contractions made to } \\
\text { resist pressure applied by the examiner to the right } \\
\text { temple }\end{array}$ & $42 \%$ & $50 \%$ & $35 \%$ & 0.33 & 0.42 \\
\hline $\begin{array}{l}\text { \#11 With the head in neutral position contractions made to } \\
\text { resist pressure applied by the examiner to the left temple }\end{array}$ & $52 \%$ & $71 \%$ & $35 \%$ & 0.84 & 0.06 \\
\hline $\begin{array}{l}\text { \#12 With the head turned to the right }\left(45^{\circ}\right) \text {, resist the } \\
\text { torsional force on the right zygoma }\end{array}$ & $42 \%$ & $57 \%$ & $29 \%$ & 0.64 & 0.14 \\
\hline $\begin{array}{l}\text { \#13 With the head turned to the left }\left(45^{\circ}\right) \text {, resist the } \\
\text { torsional force on the left zygoma }\end{array}$ & $35 \%$ & $43 \%$ & $29 \%$ & 0.32 & 0.44 \\
\hline $\begin{array}{l}\text { \#14 With the head turned to the right and tilted to the left, } \\
\text { resist applied to the left temple (left sternocleidomastoid) }\end{array}$ & $42 \%$ & $36 \%$ & $47 \%$ & -0.26 & 0.56 \\
\hline $\begin{array}{l}\text { \#15 With the head turned to the left and tilted to the right, } \\
\text { resist force applied to the right temple (right } \\
\text { sternocleidomastoid) }\end{array}$ & $35 \%$ & $43 \%$ & $29 \%$ & 0.32 & 0.44 \\
\hline $\begin{array}{l}\text { \#16 Pressure on muscle insertions: right mastoid } \\
\text { attachment of the sternocleidomastoid }\end{array}$ & $23 \%$ & $36 \%$ & $12 \%$ & 0.79 & 0.14 \\
\hline $\begin{array}{l}\text { \#17 Pressure on muscle insertions: left mastoid } \\
\text { attachment of the sternocleidomastoid }\end{array}$ & $39 \%$ & $36 \%$ & $41 \%$ & -0.13 & 0.76 \\
\hline $\begin{array}{l}\text { \#18 Pressure on muscle insertions: right suboccipital } \\
\text { attachment of the splenius capitis }\end{array}$ & $29 \%$ & $29 \%$ & $29 \%$ & 0.02 & 0.96 \\
\hline $\begin{array}{l}\text { \#19 Pressure on muscle insertions: left suboccipital } \\
\text { attachment of the splenius capitis }\end{array}$ & $35 \%$ & $29 \%$ & $41 \%$ & -0.31 & 0.47 \\
\hline $\begin{array}{l}\text { \#20 Pressure on muscle insertions: right pinna attachment } \\
\text { of the posterior auricular }\end{array}$ & $32 \%$ & $36 \%$ & $29 \%$ & 0.16 & 0.71 \\
\hline $\begin{array}{l}\text { \#21 Pressure on muscle insertions: left pinna attachment of } \\
\text { the posterior auricular }\end{array}$ & $16 \%$ & $21 \%$ & $12 \%$ & 0.39 & 0.48 \\
\hline
\end{tabular}

with cervical disorders versus those with temporomandibular dysfunction or a mixed problem.

\section{CONCLUSIONS}

A decade ago, little to no information pertaining to the characteristics of patients who respond to physical treatments of somatosensory tinnitus existed. This study showed that a multimodal physiotherapy program is efficient in decreasing tinnitus severity in individuals presenting with somatosensory components and precise clinical characteristics. In concordance with other studies on the treatment of tinnitus, it is of utmost importance to investigate and clearly define the problem presented by the individual before identifying the treatment best suited to their needs.

Notably, individuals with tinnitus that has a somatic component are susceptible to symptom improvement by participating in a physiotherapy program if (a) manifestation of the tinnitus was recent, (b) the tinnitus does not increase with loud noise exposure, (c) there is no family history of tinnitus, (d) no medication seems to increase symptoms, and (e) tinnitus modulations are triggered by somatic testing consisting of neck contractions (resistance of pressure applied to the forehead by the examiner). This study will hopefully lead to the development of decision tables for health professionals to determine the patients susceptible to experience improvement of their tinnitus symptoms.

\section{REFERENCES}

Adamchic I, Langguth B, Hauptmann C, Tass PA. (2012) Psychometric evaluation of visual analog scale for the assessement of chronic tinnitus. Am J Audiol 21:215-225.

Cherian K, Cherian N, Cook C, Kaltenbach JA. (2013) Improving tinnitus with mechanical treatment of cervical spine and jaw. J Am Acad Audiol 24:544-555.

Childs JD, Piva SR, Fritz JM. (2005) Responsiveness of the numeric pain rating scale in patients with low back pain. Spine 30:1331-1334.

Dehmel S, Pradhan S, Koehler S, Bledsoe S, Shore S. (2012) Noise overexposure alters long-term somatosensory-auditory processing in the dorsal cochlear nucleus-possible basis for tinnitus-related hyperactivity? J Neurosci 32(5):1660-1671. 
Elgoyhen AB, Langguth B. (2010) Pharmacological approaches to the treatment of tinnitus. Drug Discov Today 15(7/8):300-305.

Freeston MH, Ladouceur R, Thibodeau N, Gagnon F, Rhéaume J. (1994) L'inventaire d'anxiété de Beck: propriétés psychométriques d'une traduction française. L'Encéphale 20: $47-55$.

Ghulyan-Bédikian V, Paolino M, Giorgetti-D'Esclers F, Paolino F. (2010) Propriétés psychométriques d'une version française du Tinnitus Handicap Inventory. L'Encéphale 36:390-396.

Herraiz C. (2008) Assessing the cause of tinnitus for therapeutic options. Expert Opin Med Diagn 2:1183-1196.

Kujawa SG, Liberman MC. (2009) Adding insult to injury: cochlear nerve degeneration after "temporary" noise-induced hearing loss. $J$ Neurosci 29:14077-14085.

Langguth B, Goodey R, Azevedo A, Bjorne A, Cacace A, Crocetti A, Del Bo L, De Ridder D, Diges I, Elbert T, Flor H, Herraiz C, Sanchez TG, Eichhammer P, Figueiredo R, Hajak G, Kleinjung T, Landgrebe M, Londero A, Lainez MJA, Mazzoli M, Meikle MB, Melcher J, Rauschecker JP, Sand PG, Struve M, Van De Heyning P, Van Dijk P, Vergara R. (2007) Consensus for tinnitus patient assessment and treatment outcome measurement: tinnitus research initiative meeting, Regensburg. Prog Brain Res 166:525-536.

Levine RA. (2004) Somatic tinnitus. In: Snow JB, ed. Tinnitus: Theory and Management. Lewiston, NY: BC Decker, 108-124.

Levine RA. (2013) Tinnitus: diagnostic approch leading to treatment. Semin Neurol 33:256-269.

Levine RA, Nam EC, Oron Y, Melcher JR. (2007) Evidence for a tinnitus subgroup responsive to somatosensory based treatment modalities. Prog Brain Res 166:195-207.

Maitland G, Hengeveld E, Banks K, English K. (2005) Maitland's Vertebral Manipulation. 7th ed. Philadelphia, PA: Elsevier/ Butterworth-Heinemann.

Miller J, Gross A, D’Sylva J, Burnie SJ, Goldsmith CH, Graham N, Haines T, Brønfort G, Hoving JL. (2010) Manual therapy and exercise for neck pain: a systematic review. Man Ther 15:334-354.

Michiels S, De hertogh W, Truijen S, Van de Heyning P. (2015a) Cervical spine dysfunctions in patients with chronic subjective tinnitus. Otol Neurotol 36:741-745.

Michiels S, Van de Heyning P, Truijen S, Hertogh W. (2015b) Diagnostic value of clinical cervical spine tests in patients with cervicogenic somatic tinnitus. Phys Ther 95:1529-1535.

Michiels S, Naessens S, Van de Heyning P, Braem M, Visscher CM, Gilles A, De Hertogh W. (2016a) The effect of physical therapy treat- ment in patients with subjective tinnitus: a systematic review. Front Neurosci 10:545.

Michiels S, Van de Heyning P, Truijen S, Hallemans A, Hertogh W. (2016b) Does multi-modal cervical physical therapy improve tinnitus in patients with cervicogenic somatic tinnitus? Man Ther 26: $125-131$.

Michiels S, Van de Heyning P, Truijen S, Hallemans A, Hertogh W. (2017) Prognostic indictors for decrease in tinnitus severity after cervical physical therapy in patients with cervicogenic somatic tinnitus. Musculoskelet Sci Pract 29:33-37.

Rey-Eiriz G, Alburquerque-Sendín F, Barrera-Mellado I, MartínVallejo FJ, Fernández-de-las-Peñas C. (2010) Validity of the posterior-anterior middle cervical spine gliding test for the examination of intervertebral joint hypomobility in mechanical neck pain. J Manipulative Physiol Ther 33: 279-285.

Sanchez TG, Rocha CB. (2011a) Diagnosis and management of somatosensory tinnitus: review article. Clinics 66:1089-1094.

Sanchez TG, Rocha CB. (2011b) Diagnosis of somatosensory tinnitus. In: Moller DAR, Langguth B, DeRidder D, Kleinjung T, eds. Textbook of Tinnitus. New York, NY: Springer, 429433.

Sandmark H, Nisell R. (1995) Validity of five common manual neck pain provoking tests. Scand J Rehabil Med 27:131-136.

Shore SE, Roberts LE, Langguth B. (2016) Maladaptive plasticity in tinnitus-trigger, mechanismes and treatment. Nat Rev Neurol $12: 150-160$

Wlodyka-Demaille S, Poiraudeau S, Catanzariti JF, Rannou F, Fermanian J, Revel M. (2002) French translation and validation of 3 functional disability scales for neck pain. Arch Phys Med Rehabil 83:376-382.

Wu C, Stefanescu RA, Martel DT, Shore SE. (2016) Tinnitus: maladaptive auditory-somatosensory plasticity. Hear Res 334: $20-29$.

Young BA, Walker MJ, Strunce JB, Boyles RE, Whitman JM, Childs JD. (2009) Responsiveness of the neck disability index in patients with mechanical neck disorders. Spine 9:802-808.

Youdas JW, Garrett TR, Suman VJ, Bogard CL, Hallman HO, Carey JR. (1992) Normal range of motion of the cervical spine: an initial goniometric study. Phys Ther 72:770-780.

Zeman F, Koller M, Figueiredo R, Aazevedo A, Rates M, Coelho C, Kleinjung T, de Ridder D, Langguth B, Landgreb M. (2011) Tinnitus handicap inventory for evaluating treatment effects: which changes are clinically relevant? Otolaryngol Head Neck Surg 145: 282-287. 